\title{
ASSOCIATION OF Cladosporium cladosporioides BROWN LEAF SPOT OF LADY PALM IN PAKISTAN
}

\author{
M. Ashfaq*1 ${ }^{1}$, M.A. Anjum ${ }^{1}$, M. S. Haider ${ }^{1}$, M. Ali ${ }^{1}$, U. Mubashar ${ }^{2}$, U. Bashir ${ }^{1}$ H.M.U Aslam ${ }^{3}$ and M. Sajjad ${ }^{4}$ \\ ${ }^{1}$ Institute of Agricultural Sciences, University of the Punjab, Quaid-e-Azam Campus, Lahore, Pakistan; ${ }^{2}$ Government \\ Elementary Teachers Education College, Ghakkhar Mandi, Gujranwala, Pakistan; ${ }^{3}$ Department of Chemistry, School of \\ Science, University of Management and Technology; ${ }^{4}$ Department of Biosciences, COMSATS University, Islamabad \\ (CUI), 45550, Pakistan. \\ Corresponding Author Email: ashfaq.iags@pu.edu.pk
}

\begin{abstract}
Ladies palm (Rhapis excelsa L.) also known as broad leaf Lady palm is unique looking palm because of its appearance and beauty and, therefore, is commonly used for landscape purposes. Various fungal diseases are the major threat to Lady's palm that affects its growth and beauty. In the year 2016, diseased leaf samples were collected from different locations i.e. Pattoki, Chunian, Kot Radha Kishan, Nathoki and Grinkot of district Kasur, Punjab, Pakistan to identify the pathogen. Based on various morphological characteristics, the casual organisms Cladosporium cladosporioides were isolated, purified and identified with FCBP 1562 from collected samples. The identified pathogen was further confirmed by using molecular analysis. For this purpose, Internal Transcribed Spacer (ITS) primer pairs were used i.e. ITS1 by using universal primer pair ITS1 reverse primer (3'- TCCTCCGCTTATTGATATGC-5') and ITS1 forward primer $\left(5^{\prime}-\right.$ TCCGTAGGTGAACCTGCGG-3') for identification of casual organism from total genomic DNA of the isolated causal fungus. The pathogen was re-isolated and reconfirmed morphologically as Cladosporium cladosporioides from the artificially inoculated ladies palm plant leaves according to the Koch's postulates. To our knowledge Cladosporium cladosporioides was reported first time in Pakistan and causes chlorosis and necrosis of the lady's palm. The current study will be equally beneficial both for scientists and growers for controlling and management of this disease.
\end{abstract}

Keywords: Ladies palm, Cladosporium cladosporioides, brown spot, disease, Pakistan.

https://doi.org/10.36899/JAPS.2020.2.0060

Published online March 02, 2020

\section{INTRODUCTION}

Rhapis excelsa is an outstanding small clustering plant for shady landscape. Ladies palm have glossy, dark green palmate leaves with four to ten blunt-tipped leaf segments that grow a top slender $(<1$ inch) fiber-covered stems. Lady palm grows up to $4 \mathrm{~m}$ in height and $30 \mathrm{~mm}$ in diameter in multi-stemmed formation. Ladies palm (Rhapis excelsa L.) also known as broad leaf Lady palm is unique looking palm because of its appearance and beauty is an outstanding used as landscape purposes (Broschat, 2016).

Lady palm has high ornamental value because it easily adapts to most interiors in offices, living rooms, easily adapts to various types of soil and suitable for tropical and subtropical landscapes (Lorenzi et al., 2004). Lady palm is an expensive palm due to of its slow growth rate and limited propagation and has the ability to moderately drought tolerant (Meerow, 1992).

Fungal diseases are major threat to Ladies Palm and its commercial growers. Spots were observed on the leaf. The diseased palm leaves shows many small irregular spots, these irregular spots gave them a mosaic or mottled appearance, which is confusing or misleading some growers to speculate that the issue was caused by the virus. The disease is severe and widespread. The failure to control the disease with pesticide applications reinforced the idea that it was a viral problem, by removing damaged and diseased leaves rendered plants unsalable and causes them to loss their beauty for many months until new leaves emerged (Uchida and Nagata, 2009). The disease was observed in many plant leaves throughout the city. In September 2016, necrotic spots of ( 10.5 to $15 \mathrm{~mm}$ in diameter) were found on the leaves of Ladies palm in district Kasur, Punjab Pakistan $\left(31^{\circ} 1^{\prime} 0 \mathrm{~N}\right.$ $\left.73^{\circ} 50^{\prime} 60 \mathrm{E}\right)$. The spots were irregular in pattern on leaves. These spots merged to form a large blotch. Leaves of many plants throughout the city were affected. However, the spots were more frequent and prominent on older leaves. These spots cover whole area of leave, turn it brown and eventually die the plant.

DNA sequences are commonly used for successful identification of species. Interspecific ITS region gains a high value in identification of various fungal species (Nilsson et al., 2008). The internal transcribed spacer (ITS) region of nuclear repeats is most appropriate for identification of fungal species (Glass, 1995). ITS region is classified into two main classes ITS 1, ITS 2 and ITS 4 (Guillam et al., 1998). These were used in the identification of fungal species. Now a day's 
recent studies indicated high proficiency in identification of species using this ITS region.

Herein, it was reported first time in Pakistan that Cladosporium cladosporioides is causing chlorosis and necrosis of the lady's palm. The current study will be equally beneficial both for scientists and growers for controlling and management of this disease.

\section{MATERIALS AND METHODS}

Collection of samples and identification of pathogen: A survey based on location was conducted in different nurseries in Kasur to collect diseased samples. Fresh leaves of lady's palm with brown lesions were collected, total of 20 symptomatic leaves (Figure 1) from five locations i.e. Pattoki, Chunian, Kot Radha Kishan, Nathoki and Grinkot were collected, placed in liquid nitrogen and brought to lab for isolation of pathogen. Diseased leaves are washed and cut into small pieces $(3 \times$ $2 \mathrm{~mm}$ ), these pieces were surface sterilized with $1.5 \%$ sodium hypochlorite solution for 1-2 minutes (Jan et al., 2013) and place them on petri-plate having Malt Extract Agar (MEA) to culture them (Dhingra and Sinclair, 1995). The inoculated diseased plant leaf cultures were incubated at $25 \pm 2^{\circ} \mathrm{C}$ in incubator for 7 days till growth of fungi appears. Emerging mycelium of fungi was transferred to fresh petri-plates having growth medium (MEA) for purification to study the morphological and genetic characters of isolated pathogen.

Morphological characters of pathogen: Characterization of isolated pathogen based on morphology was carried out on 7 days old pure culture. Complete description of macroscopic characters of the fungus colony as well as microscopic features i.e. olivegreen to brown or black colonies, and have darkpigmented conidia that are formed in simple or branching chains was carried out. Colony characters include; color, size, zonation, presence of exudates, of mycelium and conidiophores (Geiser et al., 2004). Under the compound microscope shape, size, ornamentation of conidia and its attachment with the conidiophores was recorded (Domsch et al., 1980).

Genomic analysis of isolated pathogen: The genomic analysis of the pathogen was conducted by using universal primers to study the specific nuclear ribosomal Internal Transcribed Spacer (ITS) region of isolated pathogen (Alwahshi et al., 2019). Fungal colonies of causal organisms were established on agar plate and DNA of the pathogen was isolated as described by Gams et al. (2007). On the basis of isolated DNA the nucleotide sequences were generated by using PCR to ensure the good quality sequences along the entire length of amplicon and other phylogenetic analysis by using the following methods of Crous et al. (2006). On the other hand, complete genomic deoxyribonucleic acid (DNA) of the isolated pathogen was isolated using standard protocol i.e. grinding, phase separation, DNA chelation, DNA binding and DNA precipitation followed by DNA washing (Wiegand et al., 1993), from this isolated genomic DNA, ITS region was amplified in thermal cycler PCR (Martin and Rygiewicz, 2005) by using universal primer pair ITS1 reverse primer $\left(3^{\prime}-\right.$ TCCTCCGCTTATTGATATGC-5') and ITS1 forward (5'- TCCGTAGGTGAACCTGCGG-3') (Bellemain et al., 2010; White et al., 1990). The amplified ITS region was sent to ITS region nucleotides sequencing. The amplified ITS region was sequenced by different biological and bioinformatics tools and later submitted in gene bank in NCBI and the alignment and tree in TreeBASE (www.treebase.org).

Pathogenicity test: For confirmation of pathogenicity of pathogen, Koch's postulates were proved. The isolated pathogen was tested against the healthy plants. For this 1month- old Ladies palm plants in plastic pots $(25 \mathrm{~cm}$ diameter, filled with sandy soil) fully formed leaves were taken. Single isolate freshly prepared on MEA for seven days and spores suspension was prepared in sterile distilled water. Conidial count was adjusted to $1 \times 10^{6}$ spores $/ \mathrm{mL}$ and used to inject in midrib and inner surface of the leaves using sterile syringe $(0.5 \mathrm{~mL} / \mathrm{leaf})$. Control plants were injected with sterilized water. Inoculated plants were kept in green-house at $25^{\circ} \mathrm{C}$, under 12 hours of photoperiod and $90 \%$ humidity. About 15 days of post inoculation, oval shaped necrotic spots ( 8 to $12 \mathrm{~mm}$ ) of brown/olive green color were observed. The pathogen was isolated and reconfirmed morphologically which fulfilled the Koch's postulates.

\section{RESULTS AND DISCUSSION}

Cladosporium cladosporioides the pathogen with olive green, velvety, reaching 3 to $4 \mathrm{~cm}$ in diameter with reverse greenish black color confirmed the pathogenicity.

Morphological Traits: Fungal colonies effuse, olive green, velvety, reaching 3 to $4 \mathrm{~cm}$ in diameter with reverse greenish black color (Luz et al., 2006; Luz et al., 2008). Conidiophores macronematous up to $300 \mu \mathrm{m}$ long, 2-5 $\mu \mathrm{m}$ thick, pale to olivaceous brown with smooth surface. Conidia formed in long branched chains, septate, ellipsoidal or limoniform, 3-10 x 2-5 $\mu \mathrm{m}$, pale brown and smooth. On the basis of morphology, the isolated pathogen was clearly identified as Cladosporium cladosporioides (Schubert, 2007). On the other hand, various molecular markers play a very important role for isolation, identification and characterization of the various pathogenic strains through molecular analysis (Guzman et al., 1999; Jaiswal et al., 2007).

A tube of pure culture of pathogen was submitted in Institute of agricultural sciences, Punjab 
University, Quaid-e-azam campus, Lahore, Pakistan in First Fungal culture bank of Pakistan, under accession number FCBP 1562.

Inter Transcribed Spacer (ITS) Region Analysis: A pair of ITS1/ITS4 primers (forward and reverse) amplified the ITS1-5.8S rDNA-ITS4 region of genome of fungi (Nawade et al., 2017) and a single compact amplified DNA band of approximately 552bp in sizes was perceived on $1 \%$ agarose gel (Figure 2). The nucleotides sequence of ITS region obtained from gene sequence was BLAST (Zhang, et al., 2000; Morgulis et al., 2008) using the European Bioinformatics Institute (EBI) bioinformatics and National Center for Biotechnology Information (NCBI) websites and deposited in GenBank database (Accession No. MG701131).

DNA sequencing and other nuclear ribosomal DNA internal transcribed spacers ITS primers have been widely used to analyze the interspecific and intraspecific relationships, to reveal phylogenetic relationship in diverse types of fungi. The genus Cladosporium is one of the most prevalent and widespread among fungal genera (Soll, 2000).

Application of polymerase chain reaction (PCR) technology is the quickest, easiest and authentic approach for the identification pathogenic fungi. This approach is more advantages over lengthy culturing of morphological identification. Such types of techniques are commonly used as tools in classification, identification and genomic fingerprinting of various species that specifically rely on ITS universal primers (Miah et al., 2013). Similar work of fungal identification specifically the Cladosporium cladosporioides on basis of morphological and genetic molecular analysis was reported by Bensch et al. (2010).

The BLAST analysis of the nucleotide sequence showed that the fungal isolates were $100 \%$ identical (Figure 3) with other cultures of Cladosporium cladosporioides in GenBank (Accession No. KJ767066.1). The complete similarity of the sequence between our isolate and that deposited in gene bank confirmed that the causing organism of brown leaf spot of ladies' palm in Pakistan is Cladosporium cladosporioides.

Koch's Postulates Confirmation: To prove Koch`s Postulates, the manually infected plants showed similar symptoms after 7 days of manual infection that were observed primarily on the diseased plants. The pathogen was isolated and reconfirmed morphologically as Cladosporium cladosporioides. fulfilled the Koch's postulates.
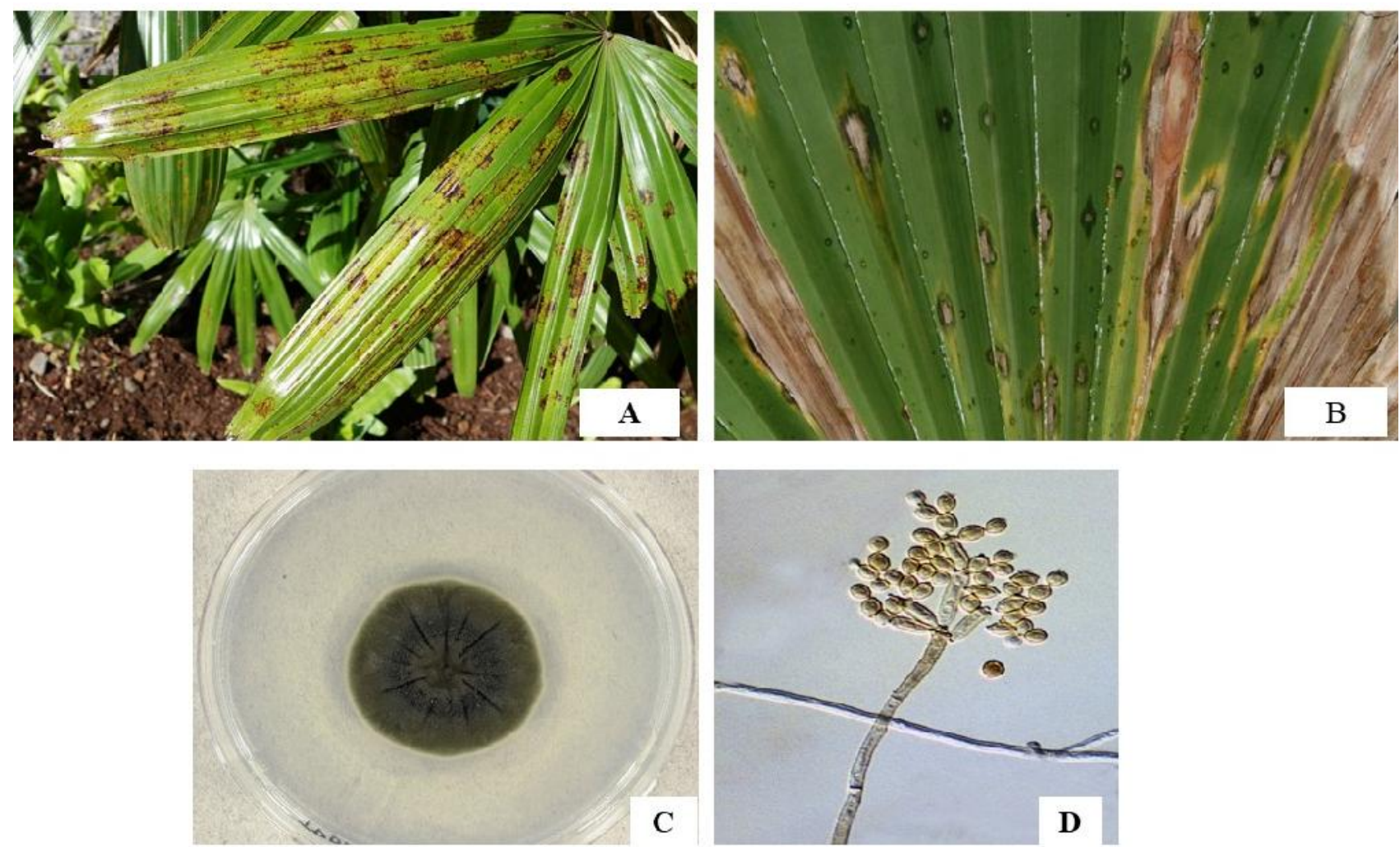

Figure 1. A, B showing symptoms on leaves, C: fungal growth D: spores of isolated fungi observed under compound microscope 


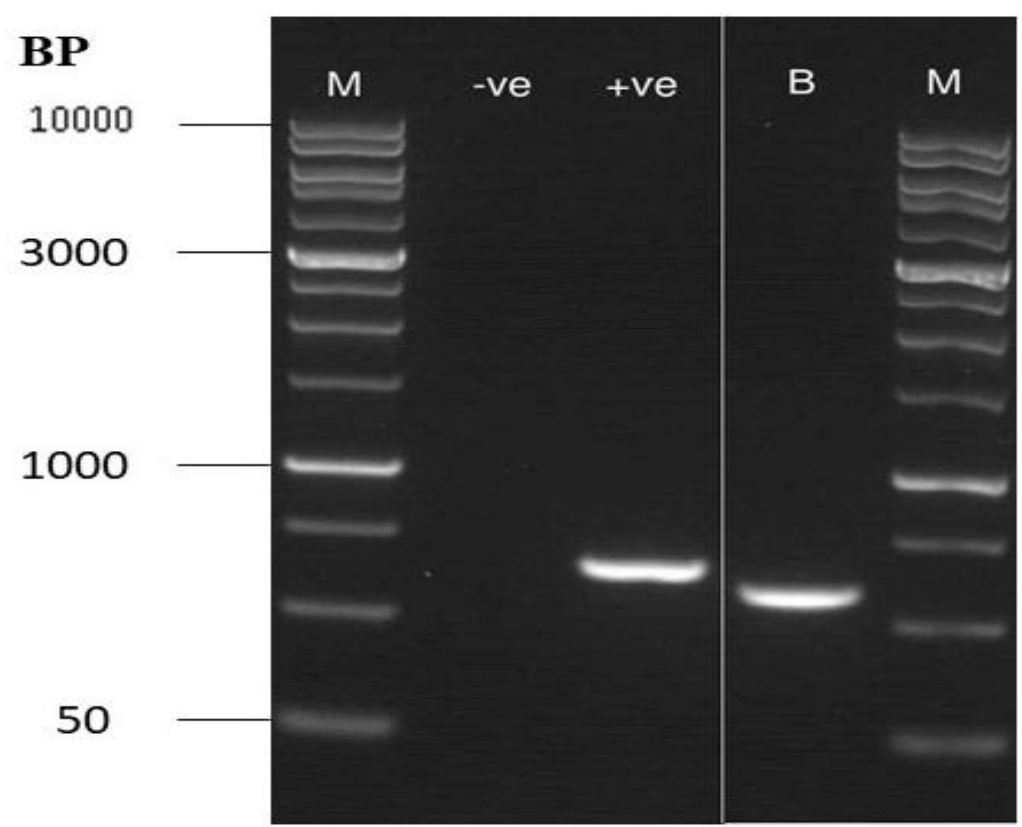

Figure 2: Gel picture showing one compact band of Amplified Internal Transcribed Spacer (ITS) region using polymerase chain reaction $(\mathrm{PCR})$

\section{Phylogenetic Tree}

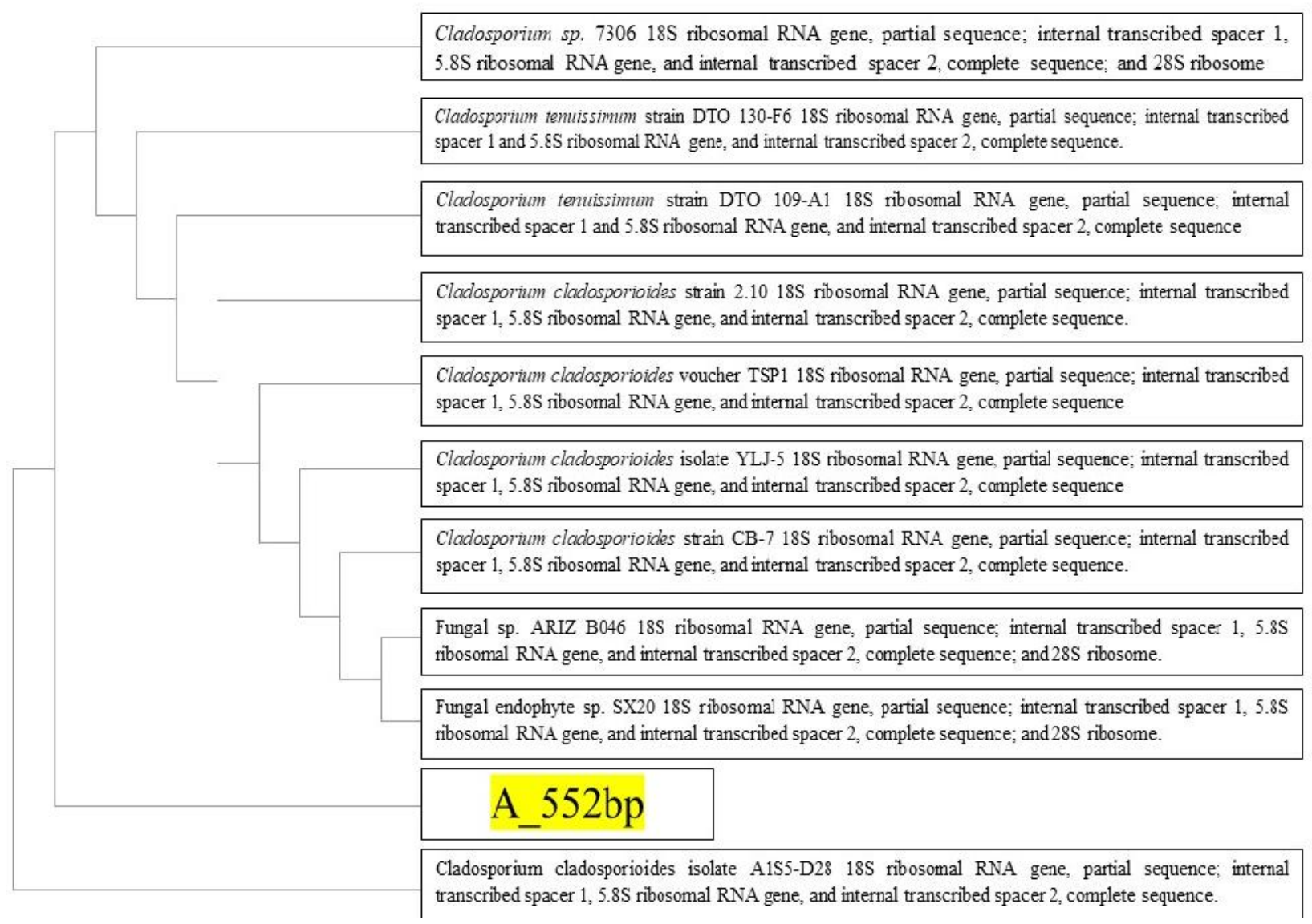

Figure 3. Phylogenetic tree of 552 bp gene showing similarity with Cladosporium cladosporioides which confirms the identified specie is Cladosporium cladosporioides (NCBI). 
Conclusion: The complete similarity of the sequence our isolate with that deposited in gene bank and symptom similarity in Koch's postulate confirmed that the causing organism of brown leaf spot of ladies' palm in Pakistan is Cladosporium cladosporioides. This first report on brown leaf spot in ladies' palm will be used as guide to control and manage the disease in Pakistan.

Acknowledgements: The authors are very thankful to the Higher Education Commission (HEC) and University Grant Commission (UGC), University of the Punjab for the assistance of financial support to complete this research work timely.

\section{REFERENCES}

Alwahshi, K.J., E.E. Saeed, A. Sham, A.A. Alblooshi, M.M. Alblooshi, K.A. El-Tarabily and S.F. AbuQamar (2019). Molecular Identification and Disease Management of Date Palm Sudden Decline Syndrome in the United Arab Emirates. Int. J. Mol. Sci. 20: 1-18.

Bellemain, E., T. Carlsen, C. Broxhmann, E. Coissac, P. Taberlet and H. Kauserud (2010). ITS as an environmental DNA barcode for fungi: an in silico approach reveals potential PCR biases. BMC. Microbiol. 10: 3-9.

Bensch, K., J.Z. Groenewald, J. Dijksterhuis and M. Starink-Willemse (2010). Species and ecological diversity within the Cladosporium cladosporioides complex (Davidiellaceae, Capnodiales). Stud. Mycol. 67: 1-94.

Broschat, T.K. (2016). Rhapis excels- Lady Palm. The University of Florida Extension Service, IFAS.

Crous, P.W., J.Z. Groenewald, M. Groenewald, P. Caldwell, U. Braun and T.C. Harrington (2006). Species of Cercospora associated with grey leaf spot of maize. Studi. Mycol. 55: 189-197.

Dhingra, O.D. and J.B. Sinclair (1995). Basic Plant Pathology Methods. CRS Press, Inc. Boca Raton, Florida, pp.335.

Domsch, K. H., W. Gams and T. Anderson (1980). Compendium of soil fungi (Academic Press, Ltd. London, United Kingdom).

Gams, W., G.J.M. Verkleij and P.W. Crous (2007). CBS Course of Mycology, 5th ed. Centraalbureau voor Schimmelcultures, Utrecht, Netherlands.

Geiser, D.M., M. Mar Jime, N.Gasco, S. Kang, I. Makalowska, N. Veeraraghavan, T.J. Ward, N. Zhang, G.A. Kuldau and K.O. Donnell (2004). A DNA sequence database for identifying Fusarium. Europ. J. P1. Pathlo. 110: 473-479.

Glass, N.L. and G.C. Donaldson (1995). Development of primer sets designed for use with the PCR to amplify conserved genes from filamentous ascomycetes . These include: Development of
Primer Sets Designed for Use with the PCR To Amplify Conserved Genes from Filamentous Ascomycetes. Appl. Environ. Microbiol. 61(4): 1323-1330.

Guillam, M., J. Sabat, E. Barrio, J. Kano and A. Querol (1998). Rapid identification of wine yeast species based on RFLP analysis of the ribosomal internal transcribed spacer ( ITS ) region. pp. 387-392.

Guzman P., P. Gepts, S. Temple, A.B.C. Mkandawire and R.L. Gilbertson (1999). Detection and differentiation of Phaeoisariopsis griseola isolates with the polymerase chain reaction and group-specific primers. Plant Dis. 83:37-42.

Jaiswal S.K., S.L.C. Prasad, S. Sharma, S. Kumar, R. Prasad, S.P. Pandey, R. Chand and A.K. Joshi (2007). Identification of molecular marker and aggressiveness for different groups of Bipolaris sorokiniana isolates causing spot blotch disease in wheat (Triticum aestivum L.). Curr. Microbiol. 55:135-141.

Jan, A., K.M. Bhat, S.J.A. Bhat, M.A. Mir, M.A. Bhat, A. Imtiyaz and J.A. Wani (2013). 'Surface sterilization method for reducing microbial contamination of field grown strawberry explants intended for in vitro culture. Afri. J. Biotec. 12(39): 5749-5753.

Lorenzi, H., H.M. Souza, J.T.M. Costa, L.S.C. Cerqueira and E. Ferreira (2004). Brazilian and Exotics Cultivated Palms. Nova Odessa, Brazil: Instituto Plantarum.

Luz, P.B., A.R. Tavares, P.D.O.P. Paiva, L.A.L. Massoli, F.F.A. Aguiar, S. Kanashiro, G.C. Stancato and P.R.C. Landgraf (2006). Effects of nitrogen, phosphorus and potassium on early growth of seedlings of Rhapis Excelsa (Thunberg) Henry ex. Rehder (Lady Palm). Ci^encia e Agrotecnologia. 30:429-434.

Luz, P.B., P.D.O. Paiva and A.R.Tavares (2008). Effect of Foliar and Substrate Fertilization on Lady Palm Seedling Growth and Development. J. Pla. Nutri. 31(7): 1313-1320.

Martin, K. J. and P.T. Rygiewicz (2005). Fungal-specific PCR primers developed for analysis of the ITS region of environmental DNA extracts. BMC. Microbiol. 5: 1-11.

Meerow, A.W. (1992). Betrock's Guide to Landscape Palms. Cooper City, FL: Betrock Information Systems, Inc.

Miah, G., M.Y. Rafii, M.R. Ismail, A.B. Puteh, H.A. Rahim, K.N. Islam and M.A. Latif (2013). A review of microsatellite markers and their applications in rice breeding programs to improve blast disease resistance. Int. J. Mol. Sci. 14: 22499-22528. 
Morgulis, A., G. Coulouris, Y. Raytselis, T.L. Madden, R. Agarwal and A.A. Schäffer (2008). "Database Indexing for Production Mega BLAST Searches", Bioinformatics. 24:17571764.

Nawade, B., J.R.Talaviya, U.M. Vyas, K.B. Jadeja and B.A. Golakiya (2017). Diversity analysis among Fusarium oxysporum F. sp. cumini isolates using ISSR markers, spore morphology and pathogenicity. Int. J. Curr. Microbiol. App. Sci. 6: 79-87.

Nilsson, R.H., E. Kristiansson, M. Ryberg, N. Hallenberg and K.H. Larsson (2008) 'Intraspecific ITS variability in the kigdom Fungi as expressed in the internacional sequence databases and its implications for molecular species identification. Evolut. Bioinfo. 4: 193-201.

Schubert K., J.Z. Groenewald, U. Braun, J. Dijksterhuis, M. Starink, C.F. Hill, P. Zalar, G.S. de Hoog and P.W. Crous (2007). Biodiversity in the Cladosporium herbarum complex (Davidiellaceae, Capnodiales), with standardisation of methods for Cladosporium taxonomy and diagnostics. Stud. Mycol. 58: 105-156.

Soll, D.R. (2000). The ins and outs of DNA fingerprinting the infectious fungi. Clin. Microbiol. Rev. 13: 332-370.

Uchida, J.Y. and N.M. Nagata (2000). Pseudocercospora Leaf Spot of Raphis Palm. Hitahr Brief No 076. pp. 1-2.

White, T.J., T. Bruns, S. Lee and J. Taylor (1990). Amplification and direct sequencing of fungal ribosomal RNA genes for phylogenetics. In: PCR Protocols: a guide to methods and applications. (Innis MA, Gelfand DH, Sninsky JJ, White TJ, eds). Academic Press, New York, USA: pp. 315-322.

Wiegand, P., B. Budowle, S. Rand and B. Brinkmann (1993). Forensic validation of the STR systems SE33 and TC11.Int. J. Legal. Med. 105: 315320 .

Zhang, Z., S. Schwartz, L. Wagner and W. Miller (2000). "A greedy algorithm for aligning DNA sequences", J. Comput. Biol. 7(1): 203-214. 